\title{
RESEARCH
}

\section{VALUATION OF THE RELATIONSHIP BETWEEN THE END OF LIFE HOSPITALIZATION NEEDS AND EARLY PRESENTING TO PALLIATIVE CARE}

Turkish Journal of Geriatrics

DOI: 10.31086/tigeri.2021.236

2021; 24(3): 391-396

- Ufuk ÜNLÜ1

- Nagihan YILDIZ ÇELTEK ${ }^{1}$

CORRESPONDANCE

1 Ufuk ÜNLÜ

Tokat Gaziosmanpaşa University School of

Medicine, Family Medicine, Tokat, Turkey

Phone: +905417891808

e-mail: drufukunlu@gmail.com

Received: Apr 29, 2021

Accepted: Aug 22, 2021

1 Tokat Gaziosmanpaşa University School of Medicine, Family Medicine, Tokat, Turkey

\section{Abstract}

Background: For a number of reasons, hospitalizations, and the need for intensive care increases during the last months of life in patients with lifethreatening illnesses. We aimed to investigate the impact of the timing of presenting to palliative care on hospitalization (intensive care unit, palliative care and other departments inpatient services) during the end-of-life period and finally places of the death.

Methods: We conducted a retrospective analysis of the hospitalization data of adult patients who were treated in the Tokat Gaziosmanpaşa University Palliative Care Center and died between January 1, 2019, and June 30, 2020. Data that included the duration of time spent in inpatient care and the intensive care units at the end of life and the place of death were compared in relationship to their time of presentation to palliative care. Presentation timing was evaluated as early ( $>90$ days before death) or late ( $<90$ days before death) period.

Results: A total of 146 patients were included: $66.4 \%$ applied to the palliative care center in the late period and $33.6 \%$ in the early period. Their mean age was 67.4 years. The patients in the early-presenting group were found to have been hospitalized for less statistically significant time during the last six weeks of their lives $(p=0.002)$. However, the data do not show a statistically significant difference between the groups in terms of length of stay in the intensive care unit.

Conclusion: For cancer patients, earlier palliative care provides improvement in symptom control, increases their quality of life, decreases unnecessary hospitalizations.

Keywords: Palliative Care; Terminal Care; Hospitalization; Intensive Care Units; Death. 


\section{INTRODUCTION}

The number of patients in need of palliative care is increasing both in our country and throughout the world. This is a consequence of the prolongation of life expectancy alongside increasing developments in medical practice and the increase in the incidence of neurological diseases and cancer. The general principle of palliative care involves the rapid and holistic assessment of patients, including their physical, social, and spiritual needs, and treatment in order to higher life quality. Studies have demonstrated that earlier palliative care consulting increase the quality of life of the patients and reduce the need for hospitalization and intensive care at the end of life as well (1).

Studies evaluating the early application of palliative care reported that patients were more satisfied with the care and that they referred to emergency room care, hospitalization, and time in the intensive care unit (ICU) less frequently. On the other hand the fact that patients have additionally been shown to have better mood and quality of life and less depression was emphasized in the same study (2). These studies also accentuated that patients who are able to use palliative care services more effectively are more likely to die at home rather than in hospital $(1,2)$. Another study showed that the quality of life increased the most in cancer patients who started earlier palliative care (3).

The retrospective evaluation of subjects such as palliative care access timing, hospitalization periods in follow-up, intensive care needs, and the place of death are beginning to find a place in the literature. In this study, we aim to contribute to the literature by evaluating the impact of the timing of presenting to palliative care on total hospitalization (intensive care unit, palliative care and other departments inpatient services) during the end-of-life period and places of the death.

\section{MATERIAL AND METHODS}

The Tokat Gaziosmanpaşa University Palliative Care Center provides holistic treatment services, including both outpatient and inpatient. The adult terminal stage cancer patients who were treated in our palliative care center (inpatient or outpatient) and who died between January 1, 2019, and June 30,2020 , constituted the universe of our study. There were 213 patients who met these criteria; 67 who had missing data in their patient records were excluded from the study. Our study was conducted using the data obtained by a retrospective scanning of 146 patient records whose information was accessed completely. The patients in our study were examined in two groups: an early-presenting group (>90 days before death) and a late-presenting group ( $<90$ days before death), based on the date of death. The 90-day limit was determined according to the definition of early palliative care specified in similar studies in the literature $(4,5)$. The groups were analyzed in relationship to the variables of age, gender, and hospitalization in the palliative care service, other department inpatient services, intensive care unit during the last six weeks of their lives and the places of death. In the comparative analysis, the length of stay in the hospital was evaluated as "never," "short," between one and 10 days, and "long" for more than 10 days.

Ethical approval for our study was obtained from the Tokat Gaziosmanpaşa University Ethics Committee (20-KAEK-252).

The research data were analyzed with the SPSS v20 ready-made package program. Descriptive statistics (percentage, mean, and standard deviation) were used in the evaluation of the demographic data. The Chi-square test was used for comparisons between groups. The statistical significance level was accepted as $p<0.05$. 


\section{FINDINGS}

In our study, 98 (67.1\%) of the patients were male and 48 (32.9\%) were female. Their mean age was $67.4 \pm 11.8$ years. (Table 1) When evaluated according to the time of the first application to palliative care, 97 (66.4\%) patients were found to have applied during the late period and 49 (33.6\%) applied in the early period. In the late-presenting patient group, the average hospital stay was $6.79 \pm 8.92$ days, and the average intensive care stay was $2.06 \pm 5.15$ days. In the early-presenting group, the mean hospital stay was $5.32 \pm 7.21$ days, and the average intensive care stay was $2.12 \pm 4.18$ days.

Regarding the comparisons of the hospitalizations in the last six weeks of their lives, the patients in the early-presenting group were hospitalized for less statistically significant time $(p=0.002)$. When the total hospitalization stays were compared, it was seen that $38.8 \%$ of the patients in the early-presenting patients group had no hospitalization at all, and this rate was $15.5 \%$ in the late-presenting patients group. It was observed that the long-term ( $>10$ days) total hospitalization rate was significantly higher in the late-presenting patients group. In terms of inpatient treatment in palliative care and other clinical inpatient services, the patients in the early-presenting group were found to have had less statistically significant need for treatment $(p<0.001)$. Similar to the total hospitalization rates, in the comparison of inpatient service stays, the rate of no hospitalization was higher in the early admission group (55.1\%) than the late admission group (24.7\%), and the long-term hospitalization rate was found to be lower. Regarding comparison of palliative care inpatient service stay duration, it is seen that hospitalizations of the patients in the early-presenting group were shorter statistically significantly $(p<0.05)$. However, the data do not show a statistically significant difference between the groups in terms of length of stay in the ICU. Information regarding the hospitalizations of the groups is summarized in Table 2 .

When the patients' places of death were examined, no statistically significant difference was found between the patient groups. However, although approximately half (46.9\%) of the patients in the early-presenting group died at home, it is noteworthy that this rate remained at $35 \%$ in the late-presenting group. The data regarding the place of death of the patients are summarized in Table 3.

\section{DISCUSSION}

In our study which we investigated the impact of presenting timing to the palliative care center on hospitalization status in the end of life and places of death, the patients who present to palliative care center in the early period were found to have been hospitalized for less statistically significant time during the last six weeks of their lives. However, the data showed that there was no statistically significant difference between the groups in terms of length of stay in the intensive care unit. Similarly, a statistically significant difference was not found between the patient groups regarding places of death.

Table 1. Gender and age data of patients

\begin{tabular}{|c|c|c|c|c|}
\hline \multicolumn{2}{|c|}{ Variables } & $\begin{array}{c}\text { Early-presenting } \\
\text { Patients Group }\end{array}$ & $\begin{array}{c}\text { Late-presenting } \\
\text { Patients Group }\end{array}$ & Total \\
\hline \multirow{3}{*}{ Gender } & $\begin{array}{c}\text { Male } \\
\mathbf{n}(\%)\end{array}$ & $37(37.8)$ & $61(62.2)$ & $98(100)$ \\
\cline { 2 - 5 } & $\begin{array}{c}\text { Female } \\
\mathbf{n}(\%)\end{array}$ & $12(25)$ & $36(75)$ & $48(100)$ \\
\hline \multicolumn{2}{|c|}{ Age (Mean $\mathbf{2}$ SD) } & $67.8 \pm 12.9$ & $67.2 \pm 12.3$ & $67.4 \pm 11.8$ \\
\hline
\end{tabular}


Table 2. Hospitalization data

\begin{tabular}{|c|c|c|c|c|}
\hline \multicolumn{2}{|c|}{ Hospitalization } & \multirow{2}{*}{$\begin{array}{c}\text { Early-presenting } \\
\text { Patients Group } \\
\text { n (\%) }\end{array}$} & \multirow{2}{*}{$\begin{array}{c}\text { Late-presenting } \\
\text { Patients Group } \\
\text { n (\%) } \\
24(24.7)\end{array}$} & $p$ \\
\hline \multirow{4}{*}{$\begin{array}{l}\text { Inpatient Service } \\
\text { Stay }\end{array}$} & $\begin{array}{l}\text { Never } \\
\text { (0 day) }\end{array}$ & & & \multirow{4}{*}{$<0.001$} \\
\hline & $\begin{array}{c}\text { Short } \\
\text { (0-10 day) }\end{array}$ & $19(38.7)$ & $44(45.3)$ & \\
\hline & $\begin{array}{l}\text { Long } \\
\text { (>10 day) }\end{array}$ & $3(6.1)$ & $29(29.9)$ & \\
\hline & Total & 49 (100) & $97(100)$ & \\
\hline \multirow{4}{*}{$\begin{array}{l}\text { Palliative Care } \\
\text { Inpatient Service } \\
\text { Stay }\end{array}$} & $\begin{array}{l}\text { Never } \\
(0 \text { day }) \\
\end{array}$ & $31(63.3)$ & $40(41.2)$ & \multirow{4}{*}{$<0.05$} \\
\hline & $\begin{array}{c}\text { Short } \\
\text { (0-10 day) }\end{array}$ & $15(30.6)$ & $45(46.4)$ & \\
\hline & $\begin{array}{l}\text { Long } \\
\text { (>10 day) }\end{array}$ & $3(6.1)$ & $12(12.4)$ & \\
\hline & Total & 49 (100) & $97(100)$ & \\
\hline \multirow{4}{*}{ ICU Stay } & $\begin{array}{l}\text { Never } \\
(0 \text { day })\end{array}$ & $34(69.4)$ & $73(75.2)$ & \multirow{4}{*}{0.488} \\
\hline & $\begin{array}{c}\text { Short } \\
\text { (0-10 day) }\end{array}$ & $12(24.5)$ & $16(16.5)$ & \\
\hline & $\begin{array}{l}\text { Long } \\
\text { (>10 day) }\end{array}$ & $3(6.1)$ & $8(8.2)$ & \\
\hline & Total & $49(100)$ & $97(100)$ & \\
\hline \multirow{4}{*}{$\begin{array}{l}\text { Total Hospitalization } \\
\text { Stay }\end{array}$} & $\begin{array}{l}\text { Never } \\
\text { (0 day) }\end{array}$ & $19(38.8)$ & $15(15.5)$ & \multirow{4}{*}{0.002} \\
\hline & $\begin{array}{c}\text { Short } \\
\text { (0-10 day) }\end{array}$ & $21(42.8)$ & $44(45.3)$ & \\
\hline & $\begin{array}{l}\text { Long } \\
\text { (>10 day) }\end{array}$ & $9(18.3)$ & $38(39.1)$ & \\
\hline & Total & $49(100)$ & $97(100)$ & \\
\hline
\end{tabular}

*The Chi-square test was used

Table 3. Places of Death Data

\begin{tabular}{|c|c|c|c|c|}
\hline \multirow{2}{*}{ Groups } & \multicolumn{3}{|c|}{$\begin{array}{c}\text { Place of Death } \\
\text { n (\%) }\end{array}$} & ICU \\
\cline { 2 - 5 } & Home & $\begin{array}{c}\text { Inpatient Ser- } \\
\text { vices }\end{array}$ & 15(30.6) \\
\hline $\begin{array}{c}\text { Early-presenting } \\
\text { Patients Group }\end{array}$ & $23(46.9)$ & $11(22.4)$ & $21(21.6)$ & 0.09 \\
\hline $\begin{array}{l}\text { Late-presenting } \\
\text { Patients Group }\end{array}$ & $34(35)$ & $42(43.3)$ & 213 \\
\hline
\end{tabular}


Due to a decrease in performance capacity and increased symptom burden in the last six months of life, hospital admissions are frequent in palliative care patients. For various reasons such as emergency room applications, hospitalizations, and the need for intensive care, the time spent in a hospital increases during the last months of life. Researchers are endeavoring to reduce this time. In the literature, there is tremendous interest in studies directed toward reducing aggressive treatment approaches and hospitalization costs $(6,7)$. Hospitals and intensive care units, in particular, are not desirable places to die. Because of both the uneasiness that they feel regarding the discontinuation of treatment for the primary diagnosis and for a range of social and cultural reasons, patients and caregivers do not tend to prefer the palliative approach, consequently, intensive care admissions increase at the end of life (8). Even so, studies have shown that the early initiation of palliative care relieves symptom burden and leads to fewer hospital admissions during the end-of-life period $(9,10)$.

In investigating the influence of palliative care timing on the hospitalization of our patients in the last six weeks of their lives, in our study, we observed that there were statistically significantly fewer hospitalizations into inpatient services and total hospitalizations (inpatient service + intensive care) in the patient group receiving palliative care during the early period. There was no significant difference between the two groups when considering the length of the stay in the intensive care unit in the last six weeks. Although no statistically significant difference was observed, when the patients' places of death were evaluated, the rate of dying at home was found to be higher in the early palliative group in comparison to the late period group.

The study that Temel et al. (11) conducted in 2010 with patients with newly diagnosed metastatic non-small-cell lung cancer brought the timing of palliative care to the agenda. In this study, two patient groups were compared who had been referred to palliative care at the time of diagnosis and continued with standard oncological treatment. Randomly assigned patients' clinic data were recorded for three years. The patients who received palliative care concomitantly with the cancer diagnosis were hospitalized less, received less chemotherapy, and had a higher quality of life at the end of their lives. In the same study, the palliative care group was found to have lived four months longer than the control group (11). In their study with advanced cancer patients, especially in their investigation of the effectiveness and timing of outpatient palliative care treatment, Blackhall et al. (9) showed that, although they applied to their centers in the last three to four months of their lives, the patients needed less hospitalization. The results of our study as earlier palliative care decrease hospitalization at the end of life, are similar to those of others in the literature.

The Robbins et al. (4) in retrospective cohort study utilizing hospital and hospice administrative databases study, which investigated the effects of palliative care consultation timing, found that early stage patients whose palliative care admissions were 90 days before death had fewer hospitalizations and that their intensive care needs especially decreased. In a retrospective cohort study by Romano et al. (2), patients with advanced stage cancer were examined in two groups: those receiving early palliative care and those receiving standard oncological treatment. These authors found that the control group had more statistically significant intensive care hospitalizations than the palliative care group. However, there was no difference between the groups when the duration of the intensive care stays and the intensive care procedures were evaluated (2). In our study, no statistically significant difference was observed between the early and the late palliative care patient groups in the evaluation of the length of stay in the intensive care unit. The reason for this may be the low number of patients and variety of diagnosis of our patients.

Most individuals with life-threatening illnesses want to die at home rather than in a hospital. In this 
respect, the place of death can be considered as one of the quality indicators of end-of-life care (12). The Blackhall et al. (9) study found that the control group died in a hospital at a higher rate in comparison to the palliative care group. Similarly, the study by Romano et al. (2) found that the death rate in the hospital and intensive care units was reported to be lower in the patient group receiving early palliative care. Although no statistically significant difference was found between the early and the late palliative patient groups in our study, the rate of death at home was higher in the early-presenting palliative patient group in comparison to the late-presenting patient group.

The limitations of our study include the fact that our study was conducted in a single center, a small number of patients were included in the study.

\section{REFERENCES:}

1. Khandelwal N, Kross EK, Engelberg RA, et al.: Estimating the effect of palliative care interventions and advance care planning on ICU utilization: a systematic review. Crit Care Med 2015;43:1102-11. (PMID: 25574794)

2. Romano AM, Gade KE, Nielsen G, et al.: Early Palliative Care Reduces End-of-Life Intensive Care Unit (ICU) Use but Not ICU Course in Patients with Advanced Cancer. The Oncologist 2017;22:318-323. (PMID: 28220023)

3. Gaertner J, Siemens W, Meerpohl JJ et al. Effect of specialist palliative care services on quality of life in adults with advanced incurable illness in hospital, hospice, or community settings: systematic review and meta-analysis. BMJ. 2017;358:j2925. (PMID:28676557)

4. Robbins SG, Hackstadt AJ, Martin S, Shinall MC Jr. Implications of Palliative Care Consultation Timing among a Cohort of Hospice Decedents. J Palliat Med. 2019;22(9):1129-1132. (PMID: 30864893)

5. Hui D, Kim SH, Roquemore J, et al.: Impact of timing and setting of palliative care referral on quality of end-of-life care in cancer patients. Cancer 2014;120:1743-1749. (PMID: 24967463)

6. Cook D, Rocker G. Dying with dignity in the inten-

\section{CONCLUSION}

The findings in our study emphasized that, for terminal stage cancer patients who need frequent hospital referrals and hospitalizations due to severe symptom burden and deterioration in the quality of life, early contact with palliative care will result in improvement in symptom control, in a decrease in unnecessary hospital and intensive care hospitalizations, an increase in the patient's quality of life, and a decrease in medical expenses. These findings are in concurrence with those of the literature. Therefore, we feel that it is important that palliative care centers become widespread and that the number of competent palliative care teams be increased.

sive care unit. N Engl J Med 2014;370(26):2506-14. (PMID: 24963569)

7. Parikh RB, Kirch RA, Smith TJ, Temel JS. Early specialty palliative care-translating data in oncology into practice. N Engl J Med 2013;369(24):2347-2351. (PMID: 24328469)

8. Rothman DJ. Where we die. N Engl J Med 2014;370(26):2457-2460. (PMID: 24963563)

9. Blackhall LJ, Read P, Stukenborg G, et al.: CARE Track for Advanced Cancer: Impact and Timing of an Outpatient Palliative Care Clinic. J Palliat Med. 2016;19(1):57-63. (PMID: 26624851)

10. Zimmermanm C, Swami N, Krzyanowsla M, et al.: Early palliative care for patients with advanced cancer: A cluster-randomized controlled trials. Lancet 2014;383(9930):1721-30.( PMID: 24559581)

11. Temel JS, Greer JA, Muzikansky A, et al.: Early palliative care for patients with metastatic non-smallcell lung cancer. N Engl J Med 2010;363(8):733-742. (PMID: 20818875)

12. Wright AA, Zhang B, Ray A, et al.: Associations between end-of-life discussions, patient mental health, medical care near death, and caregiver bereavement adjustment. JAMA. 2008;300(14):1665-73. (PMID: 18840840) 